\title{
RISIKO BISNIS DAN STRUKTUR MODAL PERUSAHAAN YANG TERGABUNG DI LQ-45
}

\author{
I.G.N.O Ariwangsa \\ Jurusan Manajemen, Universitas Pendidikan Nasional, Denpasar \\ e-mail : okaariwangsa@undiknas.ac.id
}

\begin{abstract}
Abstrak
Tujuannya penelitian ini ialah pengujian pengaruh resiko bisnis dengan strutur modalnya yang tergabung Indeks LQ-45. Jenis penelitian ialah kuantitatif. Yang menjadi populasi adalah perusahaan indeks LQ-45 selama 2017-2019. Sampel ditentukannya dengan metode purposive sampling yang memiliki syarat tertentu. Data dikumpulkan dengan dokumentasi, dari pelaporan keuangannya yang berasal dari www.idx.co.id. Teknik analisis data yaitu teknik analisis regresi sederhana dengan SPSS. Diperoleh hasi akhir yakni berpengaruhnya negatif signifikan risiko bisnis pada struktur modalnya
\end{abstract}

Kata kunci: risiko bisnis, struktur modal

\begin{abstract}
The purpose of this researchis to examine the effect of business risk on the capital structure of companies that are members of the $L Q-45$ index. This type of researchis quantitative research. The population is the companies that are included in the LQ-45 index during 2017-2019. The sample determination using purposivesampling method using certain criteria. Data is collected using the documentation method, where data is obtained from financial reports which are accessed through www.idx.co.id. The data analysis technique used in this study is a simple regression analysis technique using SPSS application. The data results show that business risk has a significant negative effect on capital structure.
\end{abstract}

Keywords : business risk, capital structure

\section{Pendahuluan}

Perusahaan di dalam menjalankan usahanya tentunya membutuhkan dana untuk dapat melakukan operasi dan aktivitas perusahaan. Untuk menentukan jenis pendanaan apa yang dibutuhkan tentunya berdasarkan kepada kondisi dari perusahaan agar tujuan dapat tercapai. Keputusan pendanaan juga sangat menentukan aktivitas operasi suatu perusahaan. Untuk dapat menjaga kelangsungan hidup dan meningkatkan pertumbuhan usahanya, tentunya perusahaan membutuhkan pendanaan yang besar. Dalam pengambilan keputusan untuk pendanaan tersebut harus dilakukan secara cermat agar perusahaan memperoleh keuntungan. Struktur modal digunakan untuk menentukan baik atau tidaknya suatu pendanaan karena terkait dengan komposisi utang (Sudarno, 2013). Struktur modal merupakan komposisi pendanaan antara hutang dan ekuitas. Dalam hal ini struktur modal digunakan untuk menentukan perbandingan penggunaan antara pinjaman dan modal sendiri. Dalam pendekatan tradisional menyebutkan tentang adanya struktur modal yang optimal. Dalam hal ini struktur modal memiliki pengaruh terhadap nilai perusahaan. Struktur modal sendiri besarannya dapat diubah-ubah hinga dapat diperoleh nilai perusahaan yang optimal. Pada awalnya di tahun 1950-an dua orang ahli ekonom yaitu Modigliani dan Miller, menyebtukan bahwa struktur modal tidak memiliki pengaruh terhadap nilai perusahaan. Mereka menyebutkan bahwa penggunaan hutang yang lebih banyak akan membuat nilai perusahaan menjadi tinggi. Namun seiring dengan berjalannya waktu teori mengenai struktur modal terus berkembang.

Struktur modal yang optimal merupakan suatu tanda baik sebelum berinvestasi. Biasanya pendanaan internal menjadi pilihan pertama dari perusahaan, setelah itu baru akan menggunakan utang sebagai sumber pendanaan berikutnya. Perbandingan antara modal dengan hutangnya merupakan struktur modal. Perubahan strukturnya ini terjadi pada saat perusahaan membutuhkan pendanaan jangka panjang, dimana pendanaan sumbernya dari eksternal ataupun internal. Saat pemilihan alternative mengenai pendanaan, adapun teori 
yang digunakan adalah Pecking Order Theory yaitu yang dicari perusahaanya ialah yang resikonya rendah (Myers, S.C., \& Majluf, 1984). Oleh karena itu sumber pendanaan internal adalah pilihan dari perusahaan.Namun tidak memungkiri untuk memperoleh pendanaan dari luar, tergantung pada tingkat risikonya. Jadi dalam teori ini pemilihan pendanaan didasarkan pada prefernsi urutan, dimulai dari pendanaan tidak berisiko sampai dengan pendanaan yang berisiko tinggi. Adapun urutan sumber pendanaan adalah pendanaan internal sebagai sumber pendanaan utama, berikutnya adalah pinjaman pihak ketiga dan yang terakhir adalah penerbitan saham.

Struktur modal dapat dikatakan optimal jika harga sahamnya maksimal dengan tingkat risiko minimum atau dengan kata lain biaya yang minimum. Perkembangan suatu perusahaan dipengaruhi oleh komposisi hutang yang tinggi sehingga mempengaruhi keputusan investor untuk menanamkan modalnya (Keown et al., 2010). Stabilitas keuangan perusahaan harus dapat dijaga. Manajer berperan untuk menjaga stabilitas keuangan perusahaan, karena hal tersebut ditentukan oleh sumber pendanaan dan asset yang dimiliki perusahaan (Subramanyam, 2017).

Manajer harus dapat menentukan apakah pendanaan perusahaan dapat berasal dari dalam atau dari pinjaman (hutang). Semakin tinggi modal yang berasal dari pinjaman maka risiko pun semakin tinggi. Bahwa risiko bisnis berhubungan dengan dengan sesuatu yang tidak pasti atas pengembalian harta pada periode yang akan datang. Risiko bisnis suatu perusahaan dikatakan kecil jika permintaan produk stabil dengan harga yang konstan, dan perusahaan dapat dengan cepat menyesuaikan pada saat harga mengalami kenaikan (Puspida, 2016). Sedangkan Sutrisno (2014) menyebutkan bahwa struktur modal adalah sumber pembiayaan aktiva yang merupakan perbandingan antara modal sendiri (equity) dengan kewajiban (debt) yang digunakan untuk membiayai aktivanya. Risiko bisnis juga dapat dikatakan sebagai kemungkinan macetnya kegaitan operasional perusahaan sebagai akibat ketidakmampuan perusahaan dari sisi financial, sumber pendanaan berasal dari hutang.

Beberapa penelitan sejenis menemukan hasilnya berbeda-beda. Wairooy (2019) meneliti diperusahaan industry otomotif dan terdaftar di Bursa Efek Indonesia (BEI) dimana diperoleh infotmasi bahwa resikonya bisnis pengaruhnya positif. Penelitian oleh Lupitasari (2014) pada perusahaan property dan real estate hasilnya risikonya bisnis memiliki pengaruh yang buruk. Rubiyana dan Kristanti (2020) bahwa hasil akhirnya tak berpengaruh. Sari, dkk (2019) hasilnya ialah berpengaruh signifikan.

Salah satu jenis indeks di BEI adalah Indeks LQ-45. Saham di Indeks tersebut adalah hasil perhitungan dari 45 saham yang diseleksi berdasarkan penilaian seperti tingkat likuiditasnya dan pertimbangan kapitalisasi pasar selama satu semester, yaitu awal bulan ke2 dan awal bulan ke-8. Sehingga sahamnya mengalami perubahan. Karena sangat liquid maka para investor sangat berminat untuk membeli saham pada indeks LQ-45 dibandingkan dengan saham-saham lainnya. Salah satu komponen keuangan yang diperhatikan oleh calon investor adalah struktur modalnya. Dimana struktur modal ini pendanaannya dapat berupa modal sendiri dan juga hutang/kewajiban. Tentunya masing-masing memiliki tingkat risikonya sendiri. Tentunya investor akan sangat memperhatikan risiko bisnis perusahaan sebelum melakukan investasi pada perusahaan tersebut. Calon investor akan cenderung untuk mempertimbangkan risiko yang akan dihadapi jika melakukan investasi pada perusahaan yang tingkat risiko bisnisnya tinggi. Selain itu berdasarkan dari hasil penelitian terdahulu mengenai risiko bisnis dan struktur modal, hasil yang diperoleh berbeda-beda sehingga peneliti ingin meneliti mengenai resikonya bisnis pada struktur permodalannya. Tujuan dari penelitian ini adalah untuk mengetahui bagaimana risiko bisnis mempengaruhi sturktur modal pada perusahaan yang tergabung di indeks LQ-45 BEl.

Penggunaan pinjaman yang tinggi sebagai sumber pendanaan sangat dihindari oleh perusahaan dengan tingkat risiko bisnis yang tinggi, dikarenakan tingkat risiko bisnis yang tinggi akan memberikan kesan negatif kepada investor, dimana para penanam modal akan berpikir kembali untuk berinvestasi pada perusahaan tersebut, sehingga tidak ada sumber dana yang masuk yang berakibat kepada kesulitan perusahaan untuk memenuhi kewajibannya membayar hutang. Berdasarkan hasil penelitian Primantara \& Dewi (2016) 
mengenai pengaruhnya resiko bisnis ini dengan strutur permodalan diperoleh yaitu resikonya memiliki pengaruh buruk yang signifikan pada struktur permodalan. Maka dirumuskan hipotesisi $\mathrm{H} 1$ : resikonya bisnis memiliki pengaruh buruk signifikan pada strukturnya permodalan.

Ambarawati (2010) menyatakan bahwa risiko bisnis merupakan tidak mampunya perusahan dalam membiayai biaya operasionalnya yang disebabkan oleh ketidakpastian pendapatan di masa depan. Ketidakpastian perolehan pendapatan di masa mendatang menyebabkan perusahaan yang berisiko tinggi akan menghindari untuk menggunakan sumber pendanaan dari pinjaman, hal ini dikarenakan kemungkinan untuk tidak terpenuhinya kewajiban pemenuhan hutang juga akan meningkat. Untuk mengukurnya dengan:

\section{Risiko Bisnis $=\frac{E B I T}{\text { Total Asset }}$}

Harga saham yang maksimal dapat tercapai jika terjadi keseimbangan antara modal sendiri dengan modal asing, atau bisa disebut sebagai optimalnya struktur modal. Keuangan perusahaan sangat dipengaruhi oleh Struktur modal, sehingga harus diperhatikan faktorfaktor yang mempengaruhinya. Keuangan perusahaan dipengaruhi oleh bagus atau tidaknya struktur modal, sehingga perusahaan harus memperhatikan indikator-indikator apa saja yang mempengaruhinya. Riyanto (2010) menyebutkan struktur modal adalah pembiayan perusahaan yang berasal dari penggabungan yang spesifik antara modal sendiri dengan hutang, sedangkan Sudana (2009) menyebutkan strukturnya permodalan yang berkewajiban lama yang ditujukan untuk sumber pembelanjaan perusahaan. Tingkat risiko dan tingkat pengembalian sangat dipengaruhi oleh keseimbangan tersebut. Untuk menghitung struktur modal dapat digunakan rumus sebagai berikut :

$$
\text { LTDER }=\frac{\text { Long Term Debt }}{\text { Total Equity }}
$$

\section{Metode}

Objeknya ialah perusahaan tergabung pada Indeks LQ-45 di Bursa Efek Indonesia (BEI). Adapun yang menjadi populasi ialah perusahaan LQ-45 diBEI periode 2017-2019 sebanyak 45 perusahaan. Teknik pengambilan sampel dengan purposive sampling , menunjuk sebuah sampel dengan ciri-ciri. Adapun ciri sampel ialah: 1) Terdaftar di indeks LQ45 selama tahun 2017-2019; 2) pelaporan keuanggannya dengan rupiah;3) perusahannya nonperbankan. Dari kategori tersebut diperoleh sampel sebanyak 27 perusahaan. Jenis data ialah data kuantitatif dengan sumber data sekunder yaitu laporan keuangan 2017-2019. Datanya kemudian dihitung dengan perumusan yang sudah ditentukan sehingga diperoleh hasil besaran risiko bisnis dan struktur modal. Setelah data diperoleh maka akan diolah serta melakukan analisa dengan metode regresi sederhana menggunakan SPSS dan dibahas.

\section{Hasil Dan Pembahasan}

Hipotesisnya penelitian diuji memakai analisis regresi sederhana. Adapun hasil pengujian sebagai berikut:

Tabel 1. Model Summary

\begin{tabular}{lrrrr}
\hline Model & $\mathrm{R}$ & R Square & $\begin{array}{c}\text { Adjusted R } \\
\text { Square }\end{array}$ & $\begin{array}{c}\text { Std. Error of the } \\
\text { Estimate }\end{array}$ \\
\hline 1 & $.464^{\mathrm{a}}$ & .215 & .205 & 39.72394 \\
\hline
\end{tabular}

a. Predictors: (Constant), RisikoBisnis

Sumber : Data diolah peneliti 
Hasilnya nilai korelasi $R$ ialah 0.464 . Untuk koefisien determinasi $\left(R^{2}\right)$ ialah 0.215 . Pengaruhnya risikonya bisnis dengan strukturnya permodalan ialah $21,5 \%$, serta sisa yang ada terpengaruh variabel lainnya yang tidak ada dipenelitian.

Tabel 2. ANOVA

\begin{tabular}{clccccc}
\hline & Model & $\begin{array}{c}\text { Sum of } \\
\text { Squares }\end{array}$ & Df & $\begin{array}{c}\text { Mean } \\
\text { Square }\end{array}$ & $F$ & Sig. \\
\hline 1 & Regression & 34139.592 & 1 & 34139.592 & 21.635 & $.000^{\text {b }}$ \\
& Residual & 124661.314 & 79 & 1577.991 & & \\
& Total & 158800.906 & 80 & & & \\
\hline
\end{tabular}

a. Dependent Variable: StrukturModal

b. Predictors: (Constant), RisikoBisnis

Sumber : Data diolah peneliti

Dari pengolahan data, nilainya $\mathrm{F}$ hitung sebesar 21,635 dimana tingkat signifikansinya $0,000<0,05$, maka $\mathrm{H}_{0}$ ditolak dan $\mathrm{H}_{1}$ diterima.

Tabel 3. Coefficients ${ }^{a}$

\begin{tabular}{|c|c|c|c|c|c|c|}
\hline \multirow[t]{2}{*}{ Model } & & \multicolumn{2}{|c|}{$\begin{array}{l}\text { Unstandardized } \\
\text { Coefficients }\end{array}$} & $\begin{array}{l}\text { Standardized } \\
\text { Coefficients }\end{array}$ & \multirow[t]{2}{*}{$\mathrm{T}$} & \multirow[t]{2}{*}{ Sig. } \\
\hline & & B & Std. Error & Beta & & \\
\hline 1 & $\begin{array}{c}\text { (Constant) } \\
\text { RisiknRisnis }\end{array}$ & $\begin{array}{l}64.495 \\
-1538\end{array}$ & $\begin{array}{c}6.169 \\
331\end{array}$ & -464 & $\begin{array}{l}10.454 \\
-4.651\end{array}$ & .000 \\
\hline
\end{tabular}

a. Variable bebas: StrukturModal

Sumber : data diolah peneliti

Dari tabel coeficients, nilai a adalah 64,495 , dan nilai b adalah $-1,538$, maka persamaannya regresinya ialah:

$$
Y=64,495-1,538 X
$$

Hasil pengolahan data menunjukkan nilai t-hitung ialah $-4,651$, dan signifikansi risiko bisnis $0,000<0,05$, hal ini berarti bahwa hipotesis diterima. Risiko bisnis memiliki dampak negatif yang signifikan pada strukturnya permodalan sebesar $-4,651$. Bahwa makin besar risikonya maka makin rendahlah struktur modal. Risiko dalam Brigham dan Houston (2011) ialah posisi asset perusahaan tanpa hutang. Risiko bisnis akan rendah jika tingkat utang yang dimiliki pun rendah. Primantara \& Dewi (2016) serta Nuswandari (2013) menyebutkan adanya dampak negative yang signifikan diantara risiko bisnis dan struktur modal. Primantara \& Dewi (2016) menyebutkan bahwa risiko bisnis menentukan kelangsungan hidup perusahaan, sehingga perusahaan yang memiliki tingkat risiko bisnis yang tinggi tentunya akan lebih memilih untuk menggunakan utang yang lebih sedikit. Selain itu risiko bisnis yang tinggi akan menyebabkan perusahaan kesulitan untuk menetapkan tingkat laba yng diinginkan karena kondisi laba yang tidak stabil.

Penggunaan pinjaman yang rendah cenderung akan dilakukan oleh perusahan yang beresiko besar, untuk menghindari ketidakmampuan memenuhi kewajibannya membayar hutang. Selain itu investor cenderung akan menolak untuk melakukan penanaman modal jika berisiko besar. Dalam hal penentuan strukturnya permodalan, bagi perusahaan yang berisiko besar maka akan memilih caranya sendiri. Berdasarkan pecking order theory disebutkan bahwa perusahaan memilih sumber dana yang minim risiko. Teori ini menyebutkan bahwa terdapat urutan dalam penentuan sumber pendanaan, dimulai dari sumber internal, tetapi tidak memungkiri untuk memperoleh pendanaan dari eksternal dengan tetap memperhatikan tingkat risiko yang minimal. Untuk sumber pendanaan internal, perusahaan dapat memperolehnya 
dari laba yang dihasilkan dari operasi perusahaan. Karena lebih menggunakan dana internal, maka perusahaan harus dapat menghitung rasio pembayaran yang didasarkan atas perkiraan terhadap kesempatan untuk berinvestasi. Jika dirasa perusahaan memerlukan tambahan dana yang berasal dari eksternal, maka perlu dipertimbangkan asal atau sumber dana tersebut. Dimulai dari sumber dana yang paling kecil risikonya seperti hutang. Setelah itu barulah dilanjutkan dengan menerbitkan surat berharga seperti obligasi, dan pilihan terakhir adalah saham.

Perusahaan dalam menentukan sumber pendanaan haruslah berhati-hati, sebab kesalahan dalam penentuan sumber pendanaan dapat menyebabkan ketidakmampuan pemenuhan kewajiban untuk membayar hutang, terutama bagi yang beresiko besar. Di satu sisi perusahaannya juga membutuhkan investasi maka kondisi keuangan perusahaan haruslah sehat sehingga para penanam modal tertarik untuk menanamkan modalnya. Kesalahan dalam penentuan struktur modal tentunya dapat berakibat buruk terhadap nilai perusahaan. Lebih buruk lagi adalah ketidakmampuan perusahaan untuk memenuhi kewajibannya sebagai akibat dari penggunaan dana eksternal yang terlalu tinggi.

\section{Simpulan dan Saran}

Hasil penelitian pengaruh risiko bisnis terhadap struktur modal, dapat ditarik kesimpulan bahwa adanya pengaruh negatif signifikan antara risiko bisnis dan struktur permodalan. Disini mengandung arti semakin tinggi tingkat risiko bisnisnya maka akan semakin rendah struktur modal.

Saran penelitian ini meliputi : 1) Perusahaan agar memperhatikan pemilihan sumber pendanaan dalam struktur terlebih jika risiko perusahaan tinggi, karena para investor akan melihat tingkat kesehatan perusahan dalam melakukan investasi; 2) Bagi peneliti selanjutnya, menambahkan variabel lain agar diketahui faktornya apa saja selain dari penelitian ini dimana berpengaruh pada struktur modal..

\section{Daftar Pustaka}

Ambarawati. S. 2010. Manajemen Keuangan Lanjut. Yogyakarta: Graha Ilmu.

Brigham, E.F. dan Hosuton J. F. 2011. Essentials Of Financial Management. (Terjemahan oleh Ali) Akbar Yulianto, Salemba Empat, Jakarta. In Edisi Kesebelas

Keown, A. J., Martin, J. D., Petty, J. W., \& Jr, D. F. S. 2010. Manajemen Keuangan: Prinsip \& Penerepan. Salemba Empat.

Lupitasari. 2014. "Pengaruh Ukuran Perusahaan dan Risiko Bisnis Terhadap Struktur Modal pada Perusahaan Proferti dan Real Estate di Bursa Efek Indonesia”. Jurnal Akuntansi Universitas Udayana. 2 (1).

MA Wairooy - Jurnal Ekonomi Balance Fakultas Ekonomi Dan Bisnis, 2019 - core.ac.uk

Myers S.C., Majluf - Journal of financial economics, 1984 - Elsevier.

Nuswandari 2013. "determinan struktur modal dalam perspektif pecking order theory dan agency theory". Vol 2, No 1, 2013

Primantara, AA Ngr Ag Ditya \& Dewi, Made Rusmala. 2016. "Pengaruh Likuiditas, Profitabilitas, Risiko Bisnis, Ukuran Perusahaan, Dan Pajak Terhadap Struktur Modal" . E-Jurnal Manajemen Unud, Vol 5, No. 5 2016: 2696-2726.

Puspida, S. 2016. Pengaruh Risiko Bisnis Dan Pertumbuhan Aktiva Terhadap Struktur Modal Pada PT. Pembangkitan Jawa Bali. Jurnal IImu dan Riset Manajemen.

Rubiyana, Kristianti.,2020. "Pengaruh Profitabilitas, Struktur Aktiva, Pertumbuhan Perusahaan, Risiko Bisnis Dan Aktivitas Perusahaan Terhadap Struktur Modal". Jurnal.um-surabaya.ac.id Vol 17, No.2 (2020).

Riyanto, Bambang. 2010. Dasar-Dasar Pembelanjaan Perusahaan, Edisi 4, Cet.10. Yogyakarta. Fakultas Ekonomi dan Bisnis UGM. 
Sari dkk., 2019."Risiko Bisnis, Struktur Aktiva, Ukuran Perusahaan, Dan Pertumbuhan Penjualan ,Struktur Modal". Jurnal Ekobistek, Vol 8 No. 2 (2019).

Subramanyam, K. R. 2017. Analisis Laporan Keuangan (Edisi 11, Buku 2). Jakarta: Salemba Empat.

Sudana, I. M. 2009. Manajemen Keuangan Perusahaan Teori dan Praktik. Jakarta: Erlangga.

Sudarno. 2013. "Analisis Faktor-Faktor Yang Mempengaruhi Struktur Modal Pada Perusahaan Manufaktur Terdaftar Di Bursa Efek Indonesia Periode 2007-201”. Diponogoro Journal of Accounting. Vol. 2 No. 2. 2013

Sutrisno., 2014., Manajemen Keuangan Teori, Konsep dan Aplikasi, Ekonisia, Yogyakarta. 